\title{
Red Ear Syndrome: A systematic review of a rare syndrome
}

\author{
Juliana Baleki Borri' ${ }^{(\mathbb{D})}$, Carlos Alberto Bordini2 ${ }^{(D)}$, Hilton Mariano da Silva Junior ${ }^{1 e 3}$ (D) \\ 'Pontifícia Universidade Católica de Campinas, Campinas, São Paulo, Brasil \\ ${ }^{2}$ Centro Universitário Municipal de Franca, Franca, São Paulo, Brasil. \\ ${ }^{3}$ Hospital Municipal de Campinas Doutor Mário Gatti, Campinas São Paulo Brasil

\section{Introdução} \\ A Red Ear Syndrome (RES) é um distúrbio enigmático com aproximadamente 100 casos publicados na literatura. \\ Apesar da variabilidade da apresentação clínica da, os sintomas mais comuns incluem ataques de dor e eritema \\ da orelha. Os pacientes também podem apresentar outros sintomas durante os ataques. O distúrbio é classificado \\ nas formas idiopática e secundária, frequentemente associada a cefaleias primárias e distúrbios da parte superior \\ da coluna cervical, respectivamente. Há uma grande carência na literatura sobre a sua etiologia, fisiopatologia e \\ tratamentos.
}

\section{Objetivos}

Investigar os aspectos fisiopatológicos e clínicos das diferentes apresentações da Red Ear Syndrome.

\section{Material e Métodos}

Foi realizada uma revisão sistemática da literatura. Revisamos todos os casos publicados e 53 artigos foram selecionados seguindo as diretrizes do Preferred Reporting Items for Systematic Review and Meta-Analysis (PRISMA). Todos os 94 pacientes dos relatos de casos coletados foram categoriezados em dois grupos: idiopático ou secundário. Os grupos foram analisados separadamente e depois comparados.

\section{Resultados}

Em ambos os grupos, há uma prevalência em mulheres, ataques unilaterais são mais comuns, a duração dos ataques pode variar de segundos a horas e podem ocorrer diariamente. No grupo idiopático, 73,7\% dos pacientes tinham ataques associados a cefaleias primárias e $20 \%$ tinham ambas as condições isoladas, o gatilho mais comum foi o estímulo tátil. Por outro lado, no grupo secundário, o gatilho mais comum foi movimentos da cabeça e pescoço. Além disso, em 61,2\% dos casos a dor se estende a outras regiões além da orelha, principalmente nos casos secundários. Os pacientes também podem apresentar sintomas autonômicos e vestibulococleares. Não há um consenso sobre o tratamento, a doença parece ser refratária a várias medicações e apresenta grande variabilidade interindividual. Nos casos idiopáticos, medicamentos usados para cefaleias primárias mostraram resultados positivos no controle dos ataques.

\section{Conclusões}

Nossa revisão sistemática mostrou diferenças clínicas importantes entre RES primária e secundária. Esses resultados impactam no reconhecimento desta condição peculiar e suas variadas manifestações.

Palavras-chave: Síndrome rara, Cefaleia, Dor orofacial 